\title{
O futebol no Capitalismo: uma poética da contradição?
}

\author{
Football in Capitalism: a poetic of contradiction?
}

\section{Luis Maffei}

Universidade Federal Fluminense (UFF), Niterói / Brasil Doutorado em Letras, UFRJ luis.maffei@terra.com.br

\begin{abstract}
RESUmo: Além de seu caráter histórico e social, o futebol possui uma inegável força enquanto prática simbolicamente aberta ao poético, em vários níveis, entre os quais a complexa aprendizagem que o jogo permite, ou a intrínseca produção de inesperado que uma partida pode guardar. No entanto, num mundo em que o capitalismo se assenhoreia de tudo, maneja as regras e dimensiona os reais, como este jogo, prática tão rentável e cada vez mais parecida com o turismo, pode estabelecer-se como uma poética da contradição?
\end{abstract}

PalaVRas-CHAVE: Futebol; Capitalismo; Poética da contradição; Violência.

ABSTRACT: Besides its historical and social aspect, football has an undeniable strength as a practice symbolically open to the poetic, on several levels, among which the complex learning that the game allows, or the intrinsic production of unexpected that a game can save. However, in a world in which capitalism takes over everything, wield the rules and scale out ever reality, how this game, practice so profitable and increasingly similar to tourism, can be established as a poetic of contradiction?

KEYWORDS: Football; Capitalism; Poetic of contradiction; Violence. 
Contradição é uma das minhas palavras prediletas. Ela me sabe (num sentido também de sabor, que, como bem deflagrou Barthes, é uma contraface do saber) adequada a convívios e relação, portadora da ambiguidade quando os termos são mais de um. Aprendi com Camões, autor do texto mais polifônico que conheço, intitulado Os Lusíadas, que a contradição encerra, entre dialéticas e nãodialéticas, a tensão e a convivência, e permite o movimento, sua leitura e o novo movimento. Contradição, palavra poética, palavra de pensamento, é também palavra política, pois contradizer é exercitar a desautorização de discursos muitas vezes consagrados ou naturalizados. Interessa-me, neste espaço de reflexão breve, considerar a possibilidade da contradição como gesto que, no futebol, guarde um poder de poética subversão, resistência e reação ao capitalismo, crescentemente posto, dentro e fora do jogo e de seus subúrbios, como caminho estrito, como bem nos mostra o atento e versátil Slavoj Žižek quando pensa na "terceira via":

a verdadeira mensagem da noção de terceira via não é simplesmente que não existe segunda via, não existe alternativa efetiva ao capitalismo global, de modo que, em um tipo trocista de negação da negação pseudo-hegeliana, essa tão louvada "terceira via" nos leva de volta à primeira e única via [?] - a terceira via nada mais é que o capitalismo global com rosto humano, ou seja, a tentativa de minimizar os custos humanos da máquina capitalista global, cujo funcionamento permanece inalterado. ${ }^{1}$

O capitalismo, por ser caminho estrito, desfruta de um raro estatuto de verdade. Contradizê-lo é relativizar, ameaçar, dirimir uma autoridade que é, como todas, relativizável, ameaçável, dirimível. A pergunta talvez seja: como contradizêlo? De que maneira o futebol, no capitalismo, pode se erguer como uma poética da contradição? Parto do pressuposto de que existe uma poética do futebol. Penso isto, não por escrever poesia com futebol, pois a escrevo com muitas coisas além do futebol, mas por ver, neste jogo, claras manifestações do lírico - a capacidade de um jogo de futebol nos questionar sobre coisas de nós mesmo, estejamos ou não torcedores, olhar-nos nos olhos (desde que saibamos mais ser olhados que olhar) como as amantes que conseguem nos devolver a nós mesmos chacoalhados, é uma delas, além da clara construção de um conhecimento que não existia antes do jogo.

\footnotetext{
${ }^{1}$ ŽIŽEK. O absoluto frágil ou Por que vale a pena lutar pelo legado cristão?, p. 71.
} 
Não há alternativa ao capitalismo global e só nos resta, só resta aos defensores da "terceira via" possível, a modesta pretensão de reduzir os danos, dar uma aparência minimamente humana à máquina total? Este é o limite da política? Páginas antes da afirmação que recém-citei, Slavoj Žižek diz, a partir do que identifica como "linhagem direta entre o cristianismo e o marxismo", que ambos "deveriam lutar do mesmo lado da barricada contra o furioso ataque dos novos espiritualismos - o legado cristão autêntico é precioso demais para ser deixado aos fanáticos fundamentalistas". 2 O fanatismo fundamentalista no Brasil tem no jogador de futebol um potencial representante. Muitos futebolistas são, por razões antigas e pouco alteradas, perversamente manipuláveis, o que cria um cenário dramático cuja gravidade é apontada por poucos. Mircea Lucescu, treinador do Shakhtar Donetsk e, consequentemente, dos muitos brasileiros que engrossam as fileiras do clube ucraniano, é raro exemplo: a relação de alguns de seus/ nossos futebolistas com uma versão excessiva e irreflexiva de Deus já irritou o técnico romeno, levando-o a manifestar seu desconforto. Este caso, é claro, não pode ser visto sem que se considere a hipótese de preconceito eurocêntrico contra uns jovens de origem terceiro-mundistas, o que recrudesceria a velha oposição entre uma Europa pensante e um resto do mundo irracional e ainda perto do bárbaro.

Não obstante, o problema neopentecostal no Brasil é grave, assim como sua consequente presença no futebol brasileiro. A articulação disso com o capitalismo é perversa, como bem descreveu, em recente entrevista, Marilena Chauí:

\footnotetext{
Uma das características do neoliberalismo é a maneira como ele concebe o indivíduo, que não é entendido nem como parte de uma classe social, nem como ser em formação que vai se relacionar com o restante da sociedade. 0 indivíduo não é pensado nem como átomo nem como classe, mas como um investimento. [...] A família, a escola e o emprego passam a ter por função a rentabilidade do indivíduo [...]. As igrejas evangélicas se apropriam desse ideário e o desenvolvem por meio de uma teologia - a teologia da prosperidade, que considera cada indivíduo justamente como um investimento ou uma empresa. [...] as igrejas, além de convencerem a pessoa de que ela nasceu para vencer na vida e ser rentável, levam a ética calvinista ao máximo, explorando a crença de que ser rentável é um sinal de salvação, porque é isso que Deus espera. ${ }^{3}$
}

\footnotetext{
${ }^{2}$ ŽIŽEK. O absoluto frágil ou Por que vale a pena lutar pelo legado cristão?, p. 27.

${ }^{3}$ CHAUÍ. Sociedade brasileira: violência e autoritarismo por todos os lados, p. 10.
} 
Rentabilidade é, de fato, palavra-chave. Se foi Camões quem me ensinou o gosto pela contradição, isso se deve, inclusive, a muitas contradições que Os Lusíadas apresenta entre o prazer da letra e sua obscura rentabilidade dentro de um processo mercantil, moderno, inclusive, no seu gérmen capitalista. No neoliberalismo contemporâneo, versão brasileira, adjuvado pelas igrejas neopentecostais, pessoas são investimento, indivíduos são commodities, Deus parece ser uma espécie de Donald Trump entre The Appentrice e a Casa Branca, apenas menos fascista, pois não vale a pena perder fiéis, ou melhor, ações por motivo de explícita xenofobia ou racismo. Fanáticos fundamentalistas, muitos de nossos jogadores articulam com alguma vontade e nenhuma reflexão o discurso da fé com o da autoajuda e o da publicidade, curtindo a vida entre o comercial de tevê e dedos apontados ao céu. Faz todo o sentido.

Além-muros, um pouco menos dessa versão de Deus, mas o domínio da via única. Um dos exemplos mais tristes desse fenômeno é o Real Madri, vítima de sua fama, justamente construída ao longo de uma longa história, de promotor do futebol espetáculo. Desde alguns quinquênios, o primo mais rico da capital espanhola vem secundarizando o futebol bem jogado pela procura do puro espetáculo, o que viola uma das únicas exigências que o futebol, como qualquer esporte, precisa cumprir para ser um jogo ético: a vontade de vencer, que não obstrui a técnica de perder. Obviamente, não estou dizendo que o Real Madri, em várias de suas formações, não queira vencer, mesmo porque vence. Mas uma estatística me parece curiosa: das últimas dez edições da liga espanhola, os merengues venceram três, enquanto seus rivais de Barcelona levantaram o dobro de taças. Já na Champions League, enquanto os catalães venceram quatro das últimas dez, os madridistas conquistaram metade. A comparação apressada perspectiva os dois ricaços espanhóis apenas para salientar que, hoje, um vence mais, bem mais que o outro, e isso não se deve apenas ao fenômeno Messi: isso se deve à aproximação do Real Madri ao estatuto de espetáculo segundo o entendeu Guy Debord. Se o "espetáculo é o capital em tal grau de acumulação que se torna imagem",4 o Real Madri é o espetáculo em tal grau de acumulação que se excede

\footnotetext{
${ }^{4}$ DEBORD. A sociedade do espetáculo: comentários sobre a sociedade do espetáculo, p. 25.
} 
em ser commodity, camisa à venda na Ásia rica (mas produzida na pobre) e fetiche de turistas japoneses (e não).

Žižek escreve, pensando na diferença lacaniana entre realidade e Real, que

\begin{abstract}
"realidade" é a realidade social das pessoas envolvidas na interação e nos processos de produção, ao passo que o Real é o "abstrato" inexorável, a lógica espectral do capital que determina o que acontece na realidade social. Essa lacuna é palpável no modo como a situação econômica de um país é considerada boa e estável por economistas internacionais mesmo quando a grande maioria do povo tem um padrão de vida inferior ao que tinha antes - a realidade não importa, o que importa é a situação do capital. ${ }^{5}$
\end{abstract}

Em outras palavras, mais minhas que do pensador esloveno, o capitalismo, criador do hegemônico discurso economicocêntrico, é um fazedor de ficções que, em nada semelhantes às que interessam à poesia, criam realidades irreais, paradoxos quase risíveis. Lembro-me de um: respeitado como um raro ex-jogador preparado, ainda mais por passear com bons ternos, enquanto, em vários idiomas, não erra concordâncias, o niteroiense Leonardo, hoje em dia, é alta voz em assuntos ligados a estrutura e organização do futebol, dizendo o que diz com a autoridade de manager do Paris Saint-Germain. Mas o que é o Paris Saint-Germain? Um brinquedo adquirido pelo empresário catari Nasser Al-Khelaïfi, que precisa ser rentável enquanto for do interesse da Autoridade de Investimento do Qatar; depois, não se sabe, talvez continue interessante, como o Chelsea de Abramovich, talvez não, como o Málaga de Abdullah bin Nasser. 0 risível é que mentes como a de Leonardo investem num discurso cheio de lugares-comuns do capitalismo, como gestão, investimento e consumidor em lugar de torcedor, enquanto a prática que tem lugar em clubes como o Paris Saint-Germain é das mais primárias, quase feudais, infantis no sentido menos lúdico do termo.

Para o capitalismo, no problem, realidade e Real podem ser bem diferentes, quanto mais, talvez, melhor. Acabei de me referir ao Real Madri, que, por oposição, me fornece um rascunho de hipótese do que pode ser um pouco do que chamo de poética da contradição: não o Barcelona, mas o Atlético, o primo menos rico da capital da Espanha, time que se infiltrou no mundo dos milionários e conseguiu jogar bola no mundo do espetáculo. No mundo do futebol, da construção de um

${ }^{5}$ ŽlŽEK. O absoluto frágil ou Por que vale a pena lutar pelo legado cristão?, p. 37-38. 
abismo entre ricos e pobres, os Atléticos de 2013-2014 e 2015-2016, finalistas da Champions, foram tão pobres que levaram muitos a dizer que a elegante Liga dos Campeões virava Libertadores quando jogavam os colchoneros. Diego Simoene, um jogador que sempre foi muito inteligente e um pouco sujo, conseguiu levar seu time a resultados impressionantes, sem os atrativos turísticos que sustentam Real Madri e Barcelona, frequentemente incomodados com a competitividade dos rapazes de Simeone.

O Atlético de Madri, contraditor, consegue tangenciar a ideia de pobreza num sentido poético, camoniano talvez, numa riqueza de espírito que supera a escassez material. Lembro-me de uma sutil evidência do papel de contradição que o Atlético exerce desde antes deste futebol de hoje, miliardário apenas para pouquíssimos: a presença da flâmula alvirrubra no quarto do personagem de Antonio Banderas, pobre e gay, marginal, portanto, em duplo sentido, em La ley del deseo, filme feito em 1987 por um Pedro Almodóvar pré-consagração internacional. Para conseguir competir, o Atlético precisa saber defender, o que cria uma beleza bastante moderna. Álvaro de Campos, o mais moderno dos heterônimos pessoanos, o que arriscou e se arriscou na aventura de ser, num tempo histórico, em deslocamento e mudança, escreveu, em sua “Ode triunfal”, que "Um orçamento é tão natural como uma árvore/ E um parlamento tão belo como uma borboleta". ${ }^{6}$ Numa pobre paráfrase, um sistema tático é tão natural como um craque, e um carrinho tão belo como uma bicicleta. Nesse sentido, dos grandes times da atualidade, o Atlético é o mais moderno de todos, e, sem dúvida, muito menos turístico que seu rival do Bernabéu. Não quero dizer, com tudo isso, que não aprecio o que se considera belo neste jogo. Em texto publicado na coletânea Pequena morte - futebol-arte, organizada por Raquel Menezes e Fernando Miranda, Ricardo Pinto de Souza dedica-se justamente a' “O belo jogo". 0 ensaísta vai além da celebração do que seja imediatamente agradável numa partida de futebol, salientando como cinese central do esporte a dinâmica entre os gestos, coletivos, do jogo e o contrário:

\footnotetext{
${ }^{6}$ PESSOA. Poesia completa de Álvaro de Campos, p. 82.
} 
0 fato de leveza e velocidade serem partes fundamentais do jogo, o fato de esta pedra redonda tão leve estar sempre em movimento, apenas faz com que uma imobilidade que se tenta superar brilhe com mais força, quando a bola para, quando o que avança é derrubado, quando um passe se perde. É o contrário do jogo, o momento em que se interrompe a ilusão de que aquilo em campo é algum tipo de organismo em movimento contínuo acaba se tornando, mais que uma dissonância, um contraponto. ${ }^{7}$

Contraponto, diz Ricardo: não está também o ensaísta, quando salienta a imobilidade e o erro, interessado na contradição, como eu? Sem dúvida, pois vai além ao pensar no que extrapola o jogo jogado em outro nível lúdico, o dos discursos provocados pelo futebol: "Entre o próprio jogo e a narrativa do jogo, entre a corrida da criança ou a corrida de Pelé e aquilo que se diz da corrida de Pelé [...], é que temos a possibilidade de um belo jogo", 8 ou, digo eu, a possibilidade de uma ficção riquíssima que é poética num nível até evidente. Mais adiante em seu texto, Ricardo Pinto de Souza, a partir, inclusive, do Guy Debord que já convidei para aqui, o que pensou na "sociedade do espetáculo", avança numa preocupação que também me toma:

O que se oferece já não é mais uma obra de arte, em que a transformação faz parte de seu sentido, mas uma outra coisa, um produto - o que os comentadores esportivos mais jovens sentem tanto prazer em celebrar [...]. E ter um time, por exemplo, deixa de ser a experiência visceral de defender algo arbitrário e infinitamente pessoal e passa a ser uma decisão de consumo de um produto que, no frigir dos ovos, será sempre o mesmo. ${ }^{9}$

\section{O final do texto é tão lúcido como preocupante:}

Como todos os valores, aqueles presentes ao redor do jogo também se esgotam. Quando estes valores são explorados de forma excessiva para melhorar o caixa, e a parte muito sutil de arbítrio coletivo que está na base da paixão universal pelo jogo deixa de ser ouvida, estamos a um passo da dissolução desta paixão o que, para o dinheiro que se produz com o jogo, acaba sendo indiferente, pois sempre haverá coisas interessantes em que se investir. Não para a beleza, já que esta é mais frágil. Se o que foi construído ao longo dos últimos cem anos torna-se indiferente - apenas mais um entretenimento entre outros filmes e programas de tv -, não há como recuperar o que foi perdido. As crianças ainda jogarão bola, obviamente. Mas já não teremos o jogo. ${ }^{10}$

\footnotetext{
${ }^{7}$ PINTO DE SOUZA. O belo jogo, p. 68.

${ }^{8}$ PINTO DE SOUZA. O belo jogo, p. 69.

9 DEBORD. A sociedade do espetáculo, p. 70.

${ }^{10}$ DEBORD. A sociedade do espetáculo, p. 70-71.
} 
Sim, "sempre haverá coisas interessantes em que se investir", sabem bem os cataris, russos e outros tais que compram times de futebol. $\mathrm{O}$ que divido com Ricardo é o receio concreto de que o futebol, coisa tão viva, seja, por isso mesmo, mortal, e que o momento em que vivemos talvez seja mais perigoso que os outros por exemplo, os que levaram o futebol à apropriação direta de ditaduras pelo mundo ou o que assistiu à proliferação, em muitas partes do globo, de uma brutal violência nas arquibancadas. Cantei o Atlético de Madri como possível rascunho de uma poética da contradição, mas não posso ignorar que o Atlético só é pobre perto dos milionários, pois é milionário perto dos pobres, e que sua transformação de Champions em Libertadores é apenas uma aproximação frágil, pois abaixo do Equador é tudo bem diferente. Onde, então, buscar a poética da contradição?

Recupero uma expressão de Ricardo: torcer, ter um time é "a experiência visceral de defender algo arbitrário e infinitamente pessoal"; já consumir é bastante distinto, nada tem de visceral e permite a qualquer um de nós dizer que torce pelo Bayern de Munique, sem que precise haver qualquer convivência, ou implicação ética, entre este um de nós e o Bayern de Munique. Consumir também permite a muitos terem vários times, espalhados pelo mundo, na já velha prática burguesa de ter tudo à disposição do ato de compra. Certa poética da contradição, no espaço humano e cheio de linguagem da torcida, corpo necessariamente visceral e arbitrário, não está no desmonte do excesso contemporâneo de consumo e limpeza, tanto no jogo como nos estádios? Os estádios, ou melhor, as arenas são espaços para a família, o consumidor, o turista. Logo, são hostis ao torcedor, que, por exemplo, tem de se ver diante da hipótese (defendida, entre outros, pelos tais "comentadores esportivos mais jovens" citados por Ricardo) de ter de dividir espaço com o torcedor adversário, isto é, consumidores vestidos com a farda do time adversário. Esta tendência asseptizante só não é levada a cabo em virtude do combate policial à violência, profilaxia que hoje é capaz de promover grandes clássicos com torcida única - o que, por sua vez, já é também uma espécie de assepsia, pois a segurança para o consumidor torna-se mais garantida.

Curioso é que, por trás da assepsia desenervante do jogo e de seu ambiente (ainda bem que minha condição torcedora me encaminha geralmente a São Januário, estádio obsoleto, periférico, pulsante em sua alma antiga), há pouca 
assepsia política. O golpe de Estado que teve lugar em 2016 no Brasil foi suportado, no que tange à chamada opinião pública, por umas figuras, majoritariamente oriundas de uma classe social pouco desfavorecida, que saíram às ruas gritando "Fora Não-sei-quê" e trajando, em grande número, camisas com o escudo da CBF. O pretexto, se não me engano, passava pelo combate à corrupção. Não preciso elencar os casos de corrupção no futebol brasileiro, do monárquico João Havelange ao simpatizante do regime militar José Maria Marin, do achacador de pequenos agricultores Ricardo Teixeira ao fisiológico e carreirista Marco Polo Del Nero. Só digo que a lógica do capitalismo deu as cartas mais uma vez, não tanto, e não apenas, pela insuportabilidade de um governo, mal ou bem, à esquerda do que costuma tolerar uma elite brasileira quando sem dinheiro para ir à Flórida, mas, sobretudo, pela seletividade brasileira acerca do que se deve combater. A roupa da CBF, que custa aproximadamente $R \$ 200,00$, resgata as cores de um Brasil pelo qual essa gente pode pagar, e não importa o que esteja por trás das portas dos gabinetes das federações e da confederação, tampouco o Brasil que esses gabinetes sufocam, em vários sentidos.

Volto, então, à pergunta da qual não sairei, formulando-a de maneira levemente diferente: como, com o quê o futebol, no capitalismo, pode ser tratado, nutrido, carregado como uma poética da contradição? Talvez com o recrudescimento da violência, tanto fora como dentro de campo, em primeiro lugar para afastar o consumidor do estádio. Quanto mais chances o turista ou o cliente previr de sair ferido, ou no mínimo molestado, de uma experiência futeboleira, menos ele entenderá o jogo como entretenimento e mais se afastará dele, o que pode ajudar a recuperar um pouco do aspecto trágico do futebol. Lembro que Nelson Rodrigues nos ensinou ser "o futebol a mais feia, a mais cruel, a mais tenebrosa das paixões". ${ }^{11}$ Sendo assim, não nos cabe pensar um pouco na urgência de propor uma relação mais próxima entre a beleza e um de seus mais fecundos aliados, o horror? Um território aberto ao abjeto e à visceralidade (no que ela tem de obsceno, inclusive) não é mais poético que a limpeza sem contradição a que o capitalismo tem submetido o jogo? Portanto, precisamos da violência, não sei se a

\footnotetext{
${ }^{11}$ RODRIGUES. Os guizos radiantes de Garrincha, p. 97.
} 
das torcidas uniformizadas, mas de alguma que suje e empobreça o jogo, que transforme os estádios, e, diagonalmente, os gramados que se cercam pelos estádios, em maus lugares.

Há outra porta, que também pode ser aberta com a ajuda da violência. Volto a Slavoj Žižek: "Na constelação ética moderna [...], atestamos nossa fidelidade à Coisa ao sacrificarmos (também) a própria Coisa (da mesma maneira, Kierkegaard intima o verdadeiro cristão a odiar por amor o próprio ser amado)". ${ }^{12}$ A abjeção, a pobreza, a feiura talvez não sejam os aspectos que mais agradam ao capitalismo, mas são, sem dúvida, práticas da poesia, gozos do poético. Conhecendo Lacan muito mal, arrisco que a Coisa, no caso do futebol, é o que nos leva a permitir justamente que ele nos olhe e nos inquira, ou o que nos faz entendê-lo como o máximo de beleza no máximo de perigo e medo - da derrota, do fracasso, do semsentido da vitória, do árbitro, de um apito tão alto que nos ensurdeça. A poética da contradição pode ser também uma poética do sacrifício, que precisa, como bem ensinou o indócil Georges Bataille, de uma inteligentíssima abertura ao selvagem e ao erótico que há na violência. Segundo o lírico filósofo francês, a

violência, que não é em si mesma cruel, é, na transgressão, o feito de um ser que a organiza. A crueldade é uma das formas da violência organizada. Não é forçosamente erótica, mas pode derivar para outras formas da violência que a transgressão organiza. Como a crueldade, o erotismo é meditado. A crueldade e o erotismo se ordena no espírito possuído pela resolução de ir além dos limites do interdito. ${ }^{13}$

Meditado, mas imediato na soberania de corpos cuja soberania está sempre em relativização (claro, os sujeitos são sujeitados pelo desejo e pela incerteza), o futebol também pode possuir uma resolução "de ir além dos limites do interdito", potencializando sua crueldade e seu erotismo. Paixão cruel e tenebrosa, feia porque feia é a faceta que devolve a indivíduos que ousam inquirir-se ao olhá-lo nos olhos, o futebol será morto se faxinado por produtos que não apenas se originam do capitalismo, mas devem tudo às diversas morais do capitalismo - uma delas, a corrupção aceita, desde que esconsa, selecionada por uns olhos míopes e vesgos; outra, a crescente deserotização de um jogo, que, progressivamente, vai

\footnotetext{
12 ŽIŽEK. O absoluto frágil ou Por que vale a pena lutar pelo legado cristão?, p. 146-147.

${ }^{13}$ BATAILLE. O erotismo, p. 103.
} 
perdendo seu caráter sacrificial, num sentido batailliano (e até autossacrificial, se pensarmos com Žižek), para tornar-se diversão de famílias burguesas.

Se o futebol conseguir o estatuto de poética da contradição, poderá surgir como uma poética do Absoluto, palavra que, ao lado de descontinuidade, sobejamente ocupou o autor d'O erotismo, mas que recolho agora do pensador esloveno que tanto me acompanhou neste ensaio:

[...] o que é o Absoluto? Algo que aparece nas experiências efêmeras - digamos, no sorriso gentil de uma bela mulher ou no sorriso caloroso e afetuoso de uma pessoa que, em condições normais, pareceria feia e rude. Nesses momentos milagrosos, porém extremamente frágeis, outra dimensão se manifesta através da nossa realidade. Como tal, o Absoluto é facilmente corroído; ele escapa muito facilmente pelos nossos dedos e deve ser manuseado com o máximo de cuidado, como se fosse uma borboleta. ${ }^{14}$

O livro de Žižek que citei várias vezes se intitula, não casualmente, $O$ absoluto frágil. Não sei até que ponto consigo perceber essa dimensão de absoluto que indiretamente acabo de expor, mas, considerando que são as experiências efêmeras que o oferecem, vi-o, já neste 2016, na complexidade extrema de dois momentos em jogos de futebol. No primeiro, entre uma defesa e outra na decisão por pênaltis entre seu Manchester City e o Liverpool, na Copa da Liga Inglesa, Willy Caballero foi tomado por furtivo lacrimejo que coloriu seu táureo rosto, e escrevi, chorando junto, um poema. O segundo era de partida tão banal como seu campeonato, num dia meu tão rotineiro como qualquer quarta-feira de trabalho e ginásio. Mas, sentado numa bicicleta ergométrica, vi Rafael Bastos empatar, num gol por cobertura, de muito longe, para o América Coelho, o jogo contra o Atlético Mineiro. O lance dependeu de uma quantidade notável de fatores - o erro do goleiro, por sua vez motivado por um recuo, por sua vez... 0 banal, num justo acordo com o inesperado, me fez perceber que ainda faz sentido, não apenas ver futebol, bebê-lo e lê-lo, mas, tendo em mente o olhar de Caballero, procurar, com agonia e êxtase, a poética com que o futebol contradiga o capitalismo e nos ajude a morrer, vezes sem conta, com dignidade.

${ }^{14}$ ŽIŽEK. O absoluto frágil ou Por que vale a pena lutar pelo legado cristão?, p. 126. 
Rio de Janeiro/ Niterói, Verão de 2016.

\section{REFERÊNCIAS:}

BATAILLE, Georges. O erotismo. Trad.: Fernando Scheibe. Belo Horizonte: Autêntica, 2013.

CHAUÍ, Marilena. Sociedade brasileira: violência e autoritarismo por todos os lados. Entrevista a Juvenal Savian Filho e Laís Modelli. Cult - revista brasileira de cultura, no 209, fevereiro de 2016, p. 8-17.

DEBORD, Guy. A sociedade do espetáculo: comentários sobre a sociedade do espetáculo. Tradução Estela dos Santos Abreu. Rio de Janeiro: Contraponto, 1997.

PESSOA, Fernando. Poesia completa de Álvaro de Campos. Edição Teresa Rita Lopes. São Paulo: Companhia das Letras, 2007.

PINTO DE SOUZA, Ricardo. O belo jogo. In: MENEZES, Raquel; MIRANDA, Fernando (org.). Pequena morte - futebol-arte. Rio de Janeiro: Oficina Raquel, 2010, p. 66-70.

RODRIGUES, Nelson. Os guizos radiantes de Garrincha. In:

A pátria em chuteiras - novas crônicas de futebol. São Paulo: Companhia das Letras, 2001, p. 96-97.

ŽlŽEK, Slavoj. O absoluto frágil ou Por que vale a pena lutar pelo legado cristão? Trad.: Rogério Bettoni. São Paulo: Boitempo, 2015. 